\title{
Chronic urticaria and thyroid autoimmunity: a meta-analysis of case-control studies
}

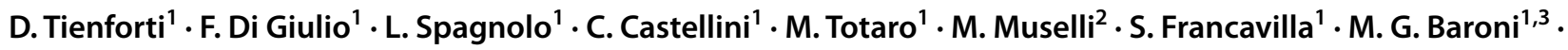 \\ A. Barbonetti ${ }^{1}$ (1)
}

Received: 3 January 2022 / Accepted: 7 February 2022 / Published online: 18 February 2022

(c) The Author(s) 2022

\begin{abstract}
Purpose Autoimmunity has been implicated in some patients with idiopathic chronic urticaria (CU). Because of the frequency of autoimmune thyroid diseases, their association with $\mathrm{CU}$ deserves special attention. We tested both the existence and the extent of an association between thyroid autoimmunity and CU.

Methods A thorough search of PubMed, Scopus, Web of Science, and Cochrane databases was performed. Studies reporting the positivity rate for anti-thyroperoxidase antibodies (TPOAbs) in people with (cases) and without CU (controls) were included. Quality of the studies was assessed by the Newcastle-Ottawa Scale. Between-study heterogeneity was assessed by Cochrane Q and $I^{2}$ tests, and the odds ratio (OR) for TPOAbs positivity was combined using random-effects models.

Results Nineteen studies provided information about TPOAbs positivity on 14,351 patients with CU and 12,404 controls. The pooled estimate indicated a more than fivefold increased risk of exhibiting TPOAbs positivity in the group with CU (pooled OR 5.18, 95\% CI 3.27, 8.22; $P<0.00001$ ). Correction for publication bias had a negligible effect on the overall estimate (pooled adjusted OR: $4.42,95 \%$ CI 2.84, 6.87, $P<0.0001)$. Between-study heterogeneity was established $\left(I^{2}=62 \%\right.$, $\left.P_{\text {for heterogeneity }}=0.0002\right)$ and when, according to meta-regression models, a sensitivity analysis was restricted to the 16 studies with the highest quality scores, the OR for TPOAbs positivity rose to $6.72(95 \% \mathrm{CI} 4.56,9.89 ; P<0.00001)$ with no significant heterogeneity $\left(I^{2}=31 \%, P_{\text {for heterogeneity }}=0.11\right)$.
\end{abstract}

Conclusions Patients with CU have a five-to-nearly sevenfold higher risk of displaying TPOAbs positivity. All patients with CU may well be offered a screening for thyroid autoimmunity.

Keywords Systematic review $\cdot$ Autoimmune thyroiditis $\cdot$ Anti-thyroperoxidase antibodies $\cdot$ Urticaria

\section{Introduction}

The term "urticaria" is widely used to define a skin manifestation characterized by the onset of itchy, fleeting wheals of variable size, shape, and distribution. These features arise from a series of pathophysiological events, including

A. Barbonetti

arcangelo.barbonetti@univaq.it

1 Andrology Unit, Department of Life, Health and Environmental Sciences, University of L'Aquila, L'Aquila, Italy

2 Epidemiology Division, Department of Life, Health and Environmental Sciences, University of L'Aquila, L'Aquila, Italy

3 Neuroendocrinology and Metabolic Diseases, IRCCS Neuromed, Pozzilli, Isernia, Italy vasodilation, increased blood flow, and vascular permeability related to the activation and degranulation of mast cells, a process that can reflect both immunological and non-immunological mechanisms. Using a temporal criterion, urticaria can be classified into acute and chronic: in chronic urticaria (CU), manifestations occur daily or nearly daily and last for more than 6 weeks $[1,2]$. In about $75 \%$ of patients, causes remain undefined, configuring the idiopathic $\mathrm{CU}$ [3]; however, many different pathogenic mechanisms have been proposed, including the occurrence of autoimmunity. Indeed, in some patients, CU may be associated with autoimmune diseases (AID) or, more generally, with positivity for autoantibodies $[4,5]$. Among the possible associations, that between $\mathrm{CU}$ and thyroid autoimmunity has attracted interest, especially because of the epidemiological dimension of the autoimmune thyroid diseases. 
The association between CU and Hashimoto's thyroiditis was first described in 1983 by Leznoff and colleagues [6], who demonstrated the presence of anti-microsomal antibodies in $12 \%$ of patients suffering from idiopathic CU (i.e., twice the frequency of controls). Since then, many case-control studies have investigated such an association [6-11]; nevertheless, with very few exceptions $[6,12,13]$, these reports have the major limitation of a low sample size and produced inconclusive results. While most studies found a significantly higher risk of thyroid autoimmunity in CU [6, 8, 12-19], some authors have found no association [20-27], while others have even documented a negative association between the two conditions [28]. Intriguingly, autoimmune thyroid diseases can also be associated with other skin disorders with autoimmune pathogenesis, namely non segmental vitiligo, where anti-thyroperoxidase antibodies (TPOAbs) can be detected [29].

On this basis, we carried out a systematic review and meta-analysis of the available case-control studies to comprehensively assess the overall risk of thyroid autoimmunity in people with diagnosis of CU.

\section{Methods}

The meta-analysis was conducted according to the Cochrane Collaboration and the Preferred Reporting Items for Systematic Reviews and Meta-Analyses (PRISMA) statement [30]; it also complies with the guidelines for Meta-Analyses and Systematic Reviews of Observational Studies (MOOSE) [31]. PRISMA and MOOSE Checklists have been presented as Supplementary Table 1 and Supplementary Table 2, respectively.

The study protocol was registered in the international prospective registry for systematic reviews (PROSPERO) with registration number: CRD42021274422.

\section{Systematic search strategy}

A systematic search was performed in PubMed, SCOPUS, Web of Science, and Cochrane Library, including the following free and vocabulary terms: "thyroid autoimmunit*", "autoimmune thyroid disease*", "TPOAb*", "anti-thyroperoxidase antibod*", "urticaria", using the Boolean functions AND/OR. The search was restricted to English language, published up to December 2021. If it was not clear from the abstract whether the study contained relevant data, the full text was retrieved. The reference lists of the identified papers were also scrutinized to find possible additional pertinent studies.

\section{Inclusion/exclusion criteria}

The outcome of interest was the relationship between $\mathrm{CU}$ and positivity for TPOAbs. The eligibility criteria were the following: (1) observational case-control studies, enrolling patients with (cases) and without CU (controls); (2) availability of odds ratio (OR) for having TPOAbs positivity or data for its calculation in both groups. Duplicates were rigorously checked and removed. Studies with missing/incomplete or unsuitable data or lacking to assess the outcome of interest were excluded. Three independent reviewers (D.T., F.D.G., and L.S.) assessed the eligibility of each selected paper; any disagreement was resolved via discussion involving a fourth reviewer (A.B.).

\section{Data extraction}

Data were extracted from the selected articles by including the first author, publication year, geographic region, mean age of participants, the number of events (TPOAbs positivity), and the total number of participants in cases and controls. Additional information, such as TPOAbs assay methods and positivity cut-offs, male-to-female ratio, levels of thyroid stimulating hormone (TSH), percentages of patients with thyroid dysfunction (hypo- and hyperthyroidism), and/ or severe urticaria (angioedema), was also extracted when available. Where data were missing or inconsistent, the authors were contacted to obtain the necessary information.

\section{Assessment of study reporting quality}

The quality of the studies was assessed using the Newcastle-Ottawa Scale (NOS) [32]. The score was calculated from 0 to 9 , and studies with a score of at least 7 were considered to be of good quality. The evaluation was performed independently by three reviewers (D.T., C.C., and M.T.), involving a fourth reviewer (A.B.) to solve any discrepancies in judgment.

\section{Statistical analysis}

The relationship between thyroid autoimmunity and CU was assessed by calculating the aggregate OR $(95 \% \mathrm{CI})$ for TPOAbs positivity comparing cases and controls. Mantel-Haenszel estimates were combined in a randomeffects model [33], which is more conservative than the fixed-effects model [34], because it accounts for heterogeneity in the calculation of the overall estimate. Studyspecific estimates, their precision, and the presence of heterogeneity among them were visualized using forest plots. The Cochran's $\chi^{2}$ (Cochran's Q) and $I^{2}$ tests were carried out to analyze statistical heterogeneity between 
the results of different studies. $I^{2}>50 \%$ and/or $P<0.05$ indicated substantial heterogeneity.

Publication bias was explored through the funnel plot [35] and the Egger's test [36]. To correct for publication bias, the Duval and Tweedie's 'trim-and-fill' analysis was carried out [37], as previously reported [38]. Briefly, in the presence of asymmetric funnel shape, this test detects putative missing studies to rebalance the distribution and provides an adjusted pooled estimate taking the additional studies into account, thus correcting the analysis for publication bias.

To detect possible sources of the between-study heterogeneity, available covariates that could affect the estimates were included in linear meta-regression models.

Data were analyzed using the $\mathrm{R}$ statistical software (version 3.6.3; R Foundation for Statistical Computing, Vienna, Austria), using the "metafor" package, and the Review Manager (RevMan) of the Cochrane Library (version 5.3; The Nordic Cochrane Centre, The Cochrane Collaboration, Copenhagen, Denmark).

\section{Results}

\section{Selection of studies}

The electronic search yielded a total of 684 articles. After removal of duplicates, 389 articles were obtained, of which 361 were excluded, because they were deemed irrelevant based on title and/or abstract reading. Thus, as shown in Fig. 1, a total of 28 articles were identified, of which 19 met the inclusion criteria $[6,8,12-28]$.

Details of the main characteristics of the papers included in the quantitative analysis are shown in Table 1.

\section{Quality of included studies}

The quality rating of the studies, based on the NOS, is presented in Table 2. The score ranged from 5 to 9 . Sixteen studies were judged to be of good quality, having been assigned a score of $\geq 7$, whereas 3 articles were of moderate quality. In particular, in the studies by Leznoff and colleagues [6] and Cho et al. [28], a possible bias arose from the definition of controls, as their clinical characteristics were not clearly defined.
Fig. 1 Flow diagram showing an overview of the study selection process
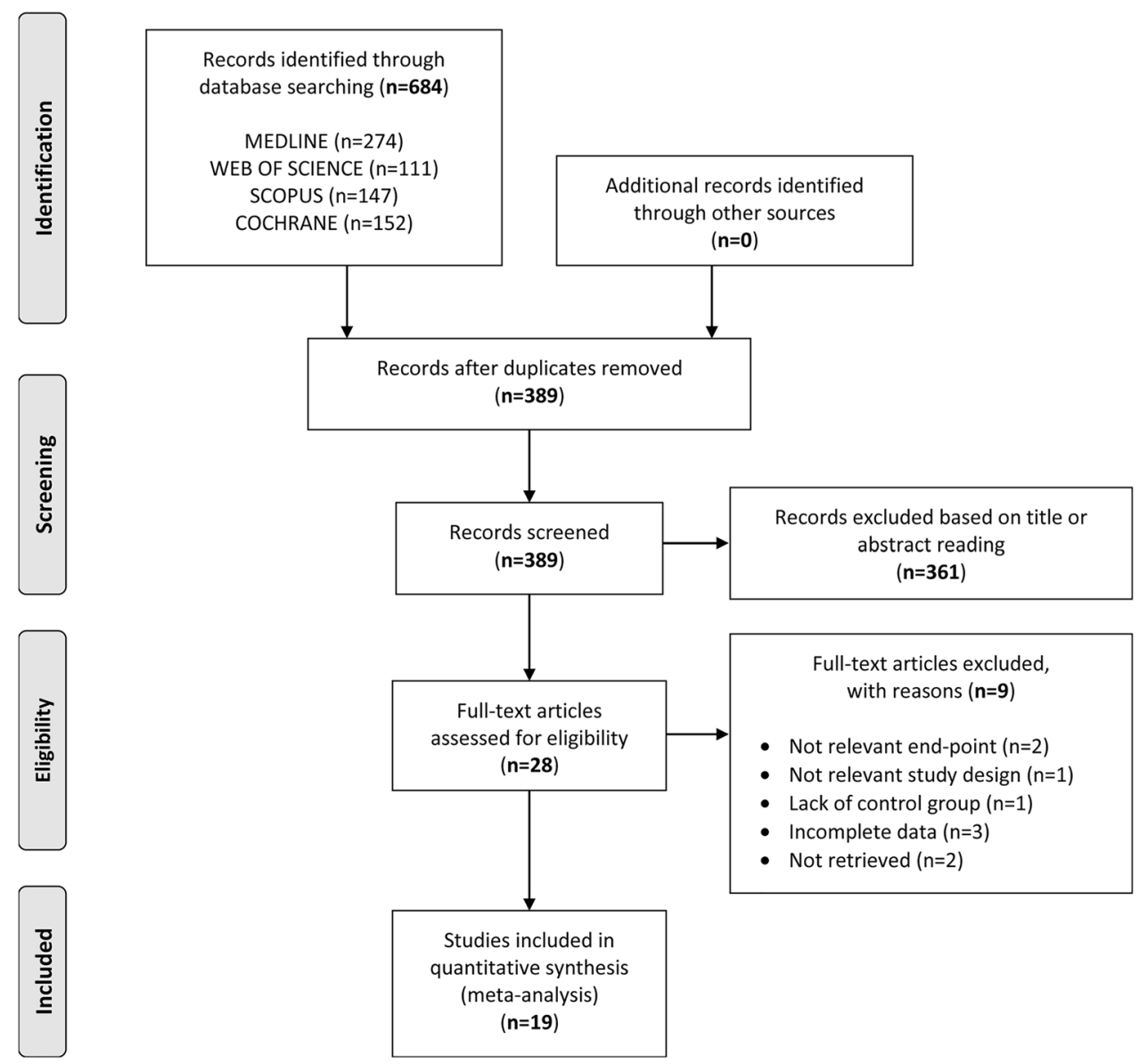


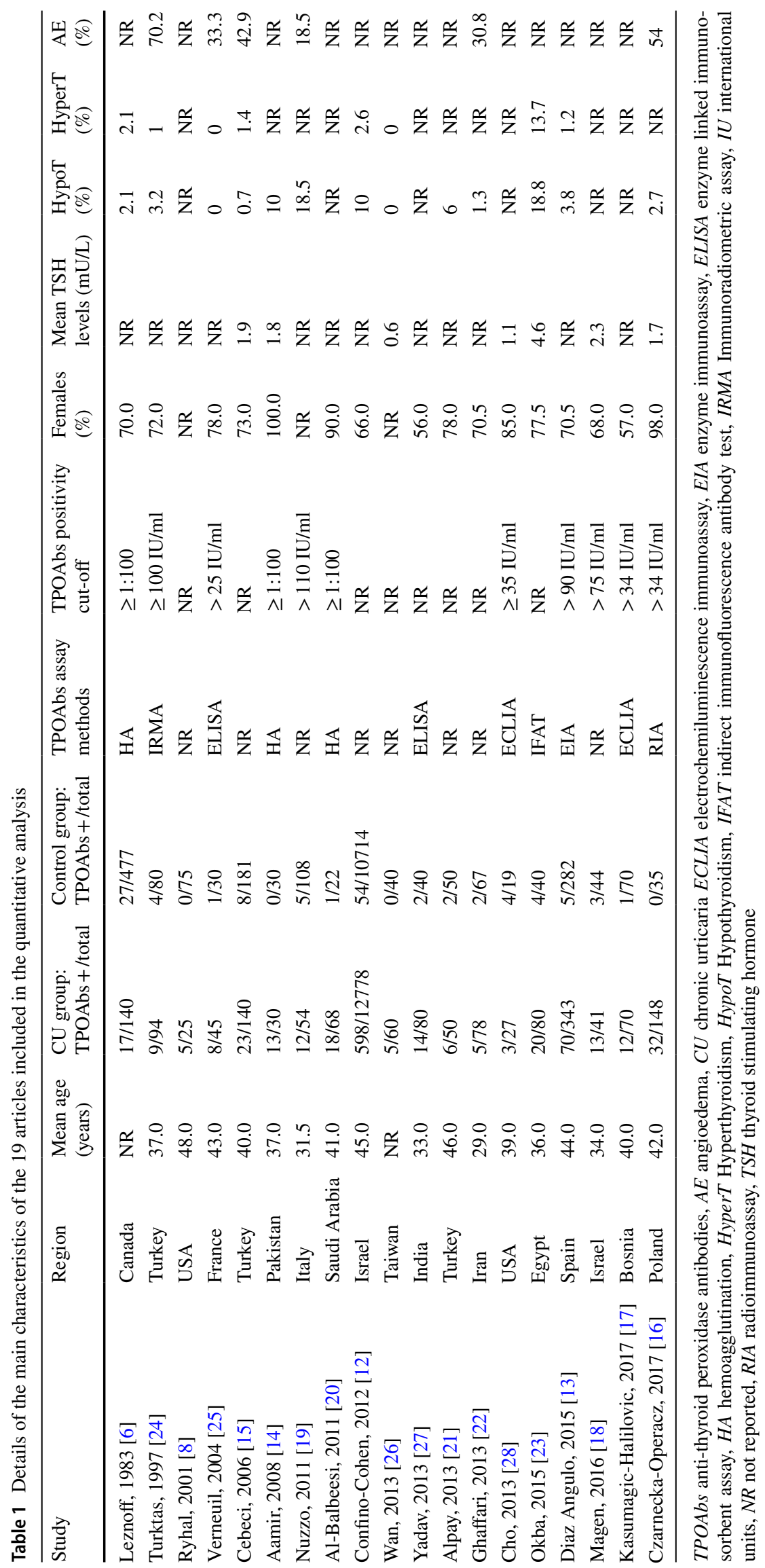




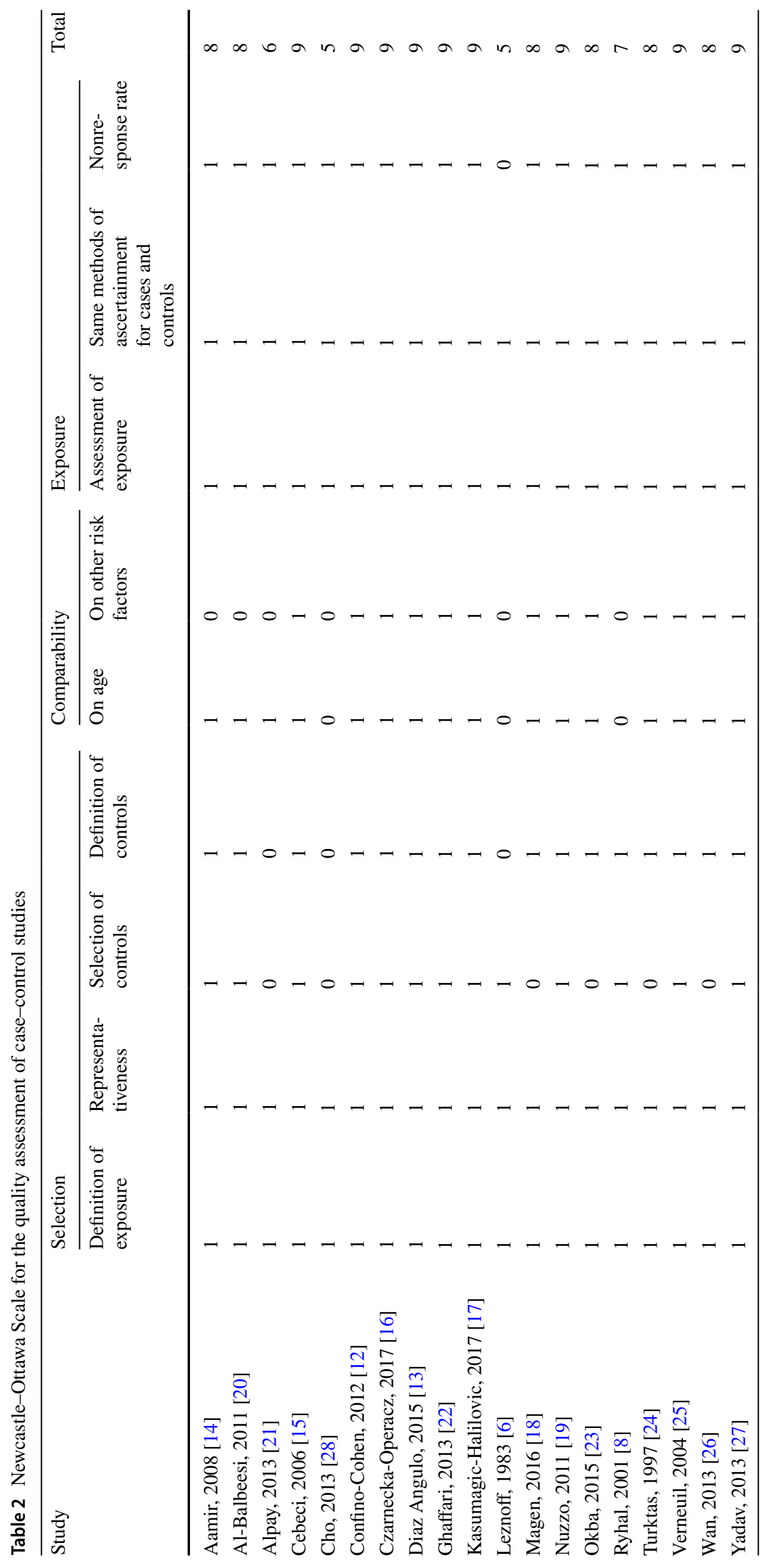




\section{Summary of results}

Overall, the 19 studies included in the meta-analysis provided information on 14,351 patients with CU (cases) and 12,404 subjects without CU (controls), resulting in an overall crude rate of TPOAbs positivity of $3.8 \%$. The pooled OR indicated a more than fivefold increased risk of exhibiting TPOAbs positivity in the group with $\mathrm{CU}$ (pooled OR 5.18, 95\% CI 3.27, 8.22; $P<0.00001$; Fig. 2). The analysis revealed a significant between-study heterogeneity $\left(I^{2}=62 \%\right.$, $P_{\text {for heterogeneity }}=0.0002$ ).

\section{Publication bias}

The asymmetrical shape of the funnel plot (Fig. 3) suggested the presence of a publication bias. Although the Egger's test revealed a not significant degree of asymmetry $(t=-1.05, P=0.31)$, the trim-and-fill test identified three putative missing studies on the left side of the distribution (Fig. 3). However, the inclusion of these additional studies resulted in a negligible effect on the overall estimate (pooled adjusted OR: 4.42, 95\% CI 2.84, 6.87, $P<0.0001$; $\left.I^{2}=58.7 \%, P_{\text {for heterogeneity }}<0.0001\right)$.

\section{Heterogeneity analysis}

As between-study heterogeneity in the pooled analysis was found (Fig. 2), linear meta-regression analyses were carried

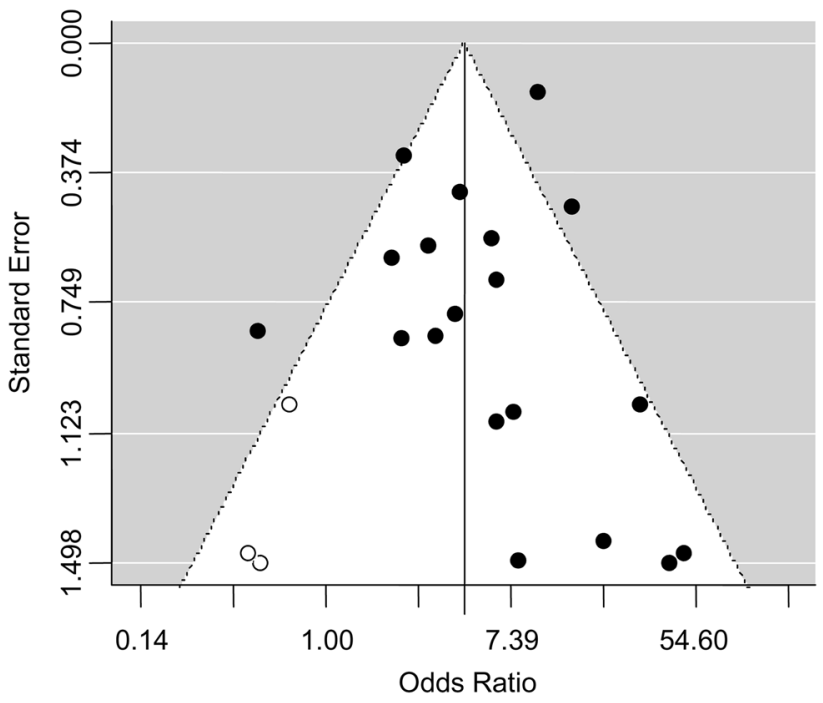

Fig. 3 Funnel plot of case-control studies of the association between chronic urticaria and thyroid autoimmunity. Trim-and-fill test identified three putative missing studies (white circles) on the left side of the distribution

out to detect possible sources of the variability. Among available covariates that could affect the estimates, including publication year, overall prevalence of thyroid autoimmunity, male-to-female ratio, TSH levels, rate of thyroid dysfunction (hypo- and hyperthyroidism), rate of severe urticaria (angioedema), and NOS quality score, only this

\begin{tabular}{|c|c|c|c|c|c|}
\hline \multirow[b]{2}{*}{ Study or Subgroup } & \multicolumn{2}{|c|}{$\mathrm{CU}$} & \multicolumn{2}{|c|}{ Controls } & \multirow[b]{2}{*}{ Weight } \\
\hline & Events & Total & Events & Total & \\
\hline Aamir et al. [14] & 13 & 30 & 0 & 30 & $2.1 \%$ \\
\hline Al- Balbeesi et al. [20] & 18 & 68 & 1 & 22 & $3.4 \%$ \\
\hline Alpay et al. [21] & 6 & 50 & 2 & 50 & $4.6 \%$ \\
\hline Cebeci et al. [15] & 23 & 140 & 8 & 181 & $8.3 \%$ \\
\hline Cho et al. [28] & 3 & 27 & 4 & 19 & $4.7 \%$ \\
\hline Confino-Cohen et al. [12] & 598 & 12778 & 54 & 10714 & $11.0 \%$ \\
\hline Czarnecka-Operacz et al. [16] & 32 & 148 & 0 & 35 & $2.2 \%$ \\
\hline Diaz-Angulo et al. [13] & 70 & 343 & 5 & 282 & $7.9 \%$ \\
\hline Ghaffari et al. [22] & 5 & 78 & 2 & 67 & $4.6 \%$ \\
\hline Kasumagic-Halilovic et al. [17] & 21 & 70 & 1 & 70 & $3.5 \%$ \\
\hline Leznoff et al. [6] & 17 & 140 & 27 & 477 & $9.4 \%$ \\
\hline Magen et al [18] & 13 & 41 & 3 & 44 & $5.8 \%$ \\
\hline Nuzzo et al. [19] & 12 & 54 & 5 & 108 & $6.9 \%$ \\
\hline Okba et al. [23] & 20 & 80 & 4 & 40 & $6.7 \%$ \\
\hline Ryhal et al. [8] & 5 & 25 & 0 & 75 & $2.0 \%$ \\
\hline Turktas et al. [24] & 9 & 94 & 4 & 80 & $6.4 \%$ \\
\hline Verneuil et al. [25] & 8 & 45 & 1 & 30 & $3.3 \%$ \\
\hline Wan et al. [26] & 5 & 60 & 0 & 40 & $2.0 \%$ \\
\hline Yadav et al. [27] & 14 & 80 & 2 & 40 & $5.1 \%$ \\
\hline Total $(95 \% \mathrm{Cl})$ & & 14351 & & 12404 & $100.0 \%$ \\
\hline Total events & 892 & & 123 & & \\
\hline $\begin{array}{l}\text { Heterogeneity: } \mathrm{Tau}^{2}=0.48 ; \mathrm{Cr} \\
\text { Test for overall effect: } \mathrm{Z}=6.99\end{array}$ & $\begin{array}{l}=47.38 \\
<0.000\end{array}$ & $\begin{array}{l}\text { df }=18 \\
\text { D1) }\end{array}$ & $=0.00$ & 12) & \\
\hline
\end{tabular}

Fig. 2 Forest plot of odds ratios for thyroid autoimmunity in subjects with and without chronic urticaria. Diamond indicates the overall estimate (width of the diamond represents $95 \% \mathrm{CI}$ ). Boxes indicate
Odds Ratio

$\mathrm{M}-\mathrm{H}$, Random, $95 \% \mathrm{Cl}$

$47.06[2.63,840.99]$

$7.56[0.95,60.34]$

$3.27[0.63,17.07]$

$4.25[1.84,9.83]$

$0.47[0.09,2.39]$

$9.69[7.33,12.82]$

$19.81[1.18,331.70]$

$14.21[5.65,35.74]$

$2.23[0.42,11.87]$

$29.57[3.85,227.25]$

$2.30[1.22,4.36]$

$6.35[1.65,24.33]$

$5.89[1.95,17.74]$

$3.00[0.95,9.48]$

$40.51[2.15,763.20]$

$2.01[0.60,6.80]$

$6.27[0.74,53.02]$

$8.03[0.43,149.32]$

$4.03[0.87,18.69]$

$5.18[3.27,8.22]$

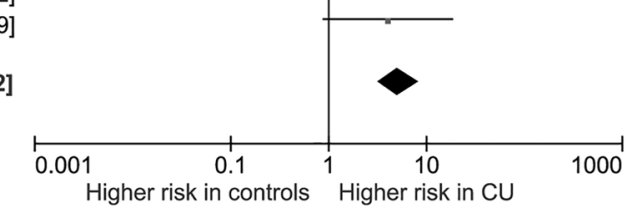

the weight of individual studies in the pooled result. $C I$ confidence interval, $C U$ chronic urticaria, $d f$ degrees of freedom, $M-H$ MantelHaenszel 
latter contributed significantly to the heterogeneity (Supplementary Fig. 1): a higher study NOS score was significantly associated with the report of a higher risk for thyroid autoimmunity in patients with CU compared to controls ( $\beta$-coefficient $=0.36,95 \%$ CI $0.15,0.58 ; P=0.001)$.

As shown in Fig. 4, when, according to the meta-regression results, a sensitivity analysis was restricted to studies with an NOS score $\geq 7$, the OR for TPOAbs positivity rose to 6.72 (95\% CI $4.56,9.89 ; P<0.00001)$ with decrease of heterogeneity to a no longer significant degree $\left(I^{2}=31 \%\right.$, $P_{\text {for heterogeneity }}=0.11$ ).

\section{Discussion}

The genesis of spontaneous CU has been considered idiopathic for many years, but the identification of autoantibodies in some patients has given rise to the new concept of "autoimmune urticaria" [39]. In this view, as immune dysregulation factors are shared by both urticaria and autoimmune thyroiditis [40, 41], it might be expected that the two entities may often coexist in the same patient. This association, albeit widely investigated, still remains somehow uncertain due to a number of limitations of the studies, including the small sample sizes, heterogeneity among the results, and the different diagnostic criteria used to define thyroid autoimmunity.

In the present meta-analysis of 19 rigorously selected case-control studies, the diagnosis of CU was associated with an approximately fivefold higher risk of exhibiting positivity for TPOAbs, a marker of chronic autoimmune thyroiditis. In the analysis restricted to studies with higher quality scores, the OR of the association increased to 6.72 (95\% CI 4.56, 9.89) with a not significant heterogeneity.

The mechanisms underlying the association between $\mathrm{CU}$ and thyroid autoimmunity are not fully elucidated. An immune-regulatory role of TSH would be supported by some evidence on the effect of levothyroxine treatment that, in some studies, led to improvements of urticaria clinical features [7, 42, 43], an effect believed to be mediated by the decrease in TSH levels [42]. However, other studies failed to demonstrate the efficacy of levothyroxine $[44,45]$, and even when an effect has been found, it was challenged by the limited sample size of the study populations together with the lack of a control group. Although the studies included in this meta-analysis largely lacked information about levothyroxine treatment, the role of TSH seems to be unlikely as meta-regression analyses showed no significant influence of either TSH levels or the rate of thyroid dysfunction (hypoor hyperthyroidism) on the association under investigation.

One of the pieces of evidence that mostly supports the autoimmune genesis of $\mathrm{CU}$ is based on the observation that $45 \%$ and $55 \%$ of patients with CU display anti-IgE and antiFceRI antibodies, respectively, whose titre exhibits a welldocumented correlation with the positivity of the autologous serum skin test [46]. The evidence of an autoimmune pathogenesis of $\mathrm{CU}$ creates the basis for theorizing the existence of common immunopathologic mechanisms shared by $\mathrm{CU}$ and autoimmune thyroiditis [40, 41]. One mediator called into play is the interleukin 6 (IL6). In vitro experiments

\begin{tabular}{|c|c|c|c|c|c|}
\hline \multirow[b]{2}{*}{ Study or Subgroup } & \multicolumn{2}{|c|}{ CU } & \multicolumn{2}{|c|}{ Controls } & \multirow[b]{2}{*}{ Weight } \\
\hline & Events & Total & Events & Total & \\
\hline Aamir et al. [14] & 13 & 30 & 0 & 30 & $1.7 \%$ \\
\hline Al- Balbeesi et al. [20] & 18 & 68 & 1 & 22 & $3.1 \%$ \\
\hline Cebeci et al. [15] & 23 & 140 & 8 & 181 & $11.7 \%$ \\
\hline Confino-Cohen et al. [12] & 598 & 12778 & 54 & 10714 & $22.8 \%$ \\
\hline Czarnecka-Operacz et al. [16] & 32 & 148 & 0 & 35 & $1.8 \%$ \\
\hline Díaz-Angulo et al. [13] & 70 & 343 & 5 & 282 & $10.5 \%$ \\
\hline Ghaffari et al. [22] & 5 & 78 & 2 & 67 & $4.4 \%$ \\
\hline Kasumagic-Halilovic et al. [17] & 21 & 70 & 1 & 70 & $3.2 \%$ \\
\hline Magen et al [18] & 13 & 41 & 3 & 44 & $6.3 \%$ \\
\hline Nuzzo et al. [19] & 12 & 54 & 5 & 108 & $8.3 \%$ \\
\hline Okba et al. [23] & 20 & 80 & 4 & 40 & $7.9 \%$ \\
\hline Ryhal et al. [8] & 5 & 25 & 0 & 75 & $1.6 \%$ \\
\hline Turktas et al. [24] & 9 & 94 & 4 & 80 & $7.3 \%$ \\
\hline Verneuil et al. [25] & 8 & 45 & 1 & 30 & $2.9 \%$ \\
\hline Wan et al. [26] & 5 & 60 & 0 & 40 & $1.6 \%$ \\
\hline Yadav et al. [27] & 14 & 80 & 2 & 40 & $5.1 \%$ \\
\hline Total $(95 \% \mathrm{Cl})$ & & 14134 & & 11858 & $100.0 \%$ \\
\hline Total events & 866 & & 90 & & \\
\hline $\begin{array}{l}\text { Heterogeneity: } \mathrm{Tau}^{2}=0.15 ; \mathrm{Ch} \\
\text { Test for overall effect: } \mathrm{Z}=9.66\end{array}$ & $\begin{array}{l}21.78, c \\
0.0000\end{array}$ & $\begin{array}{l}\mathrm{df}=15 \\
01)\end{array}$ & $P=0.11$ & $12=21$ & \\
\hline
\end{tabular}

Fig. 4 Sensitivity analysis based on the quality score at the Newcastle-Ottawa Scale (NOS): only studies with NOS score $\geq 7$ were included. Forest plot of odds ratios for thyroid autoimmunity in subjects with and without CU. Diamond indicates the overall estimate
Odds Ratio

M-H, Random, 95\% Cl

47.06 [2.63, 840.99]

$7.56[0.95,60.34]$

$4.25[1.84,9.83]$

$9.69[7.33,12.82]$

$19.81[1.18,331.70]$

$14.21[5.65,35.74]$

$2.23[0.42,11.87]$

29.57 [3.85, 227.25]

$6.35[1.65,24.33]$

$5.89[1.95,17.74]$

$3.00[0.95,9.48]$

$40.51[2.15,763.20]$

$2.01[0.60,6.80]$

$6.27[0.74,53.02]$

$8.03[0.43,149.32]$

$4.03[0.87,18.69]$

$6.72[4.56,9.89]$

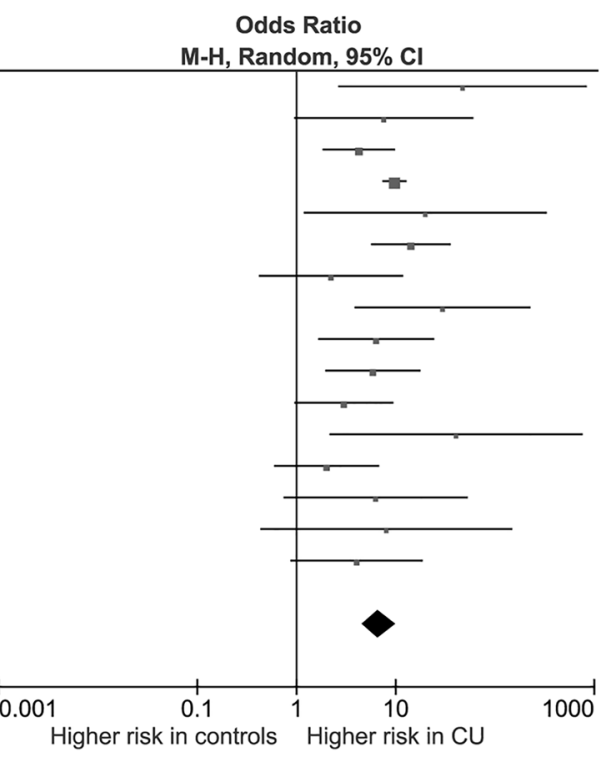

(diamond width represents $95 \% \mathrm{CI}$ ). Boxes indicate the weight of individual studies in the pooled result. $C I$ confidence interval, $C U$ chronic urticaria, $d f$ degrees of freedom, $M-H$ Mantel-Haenszel 
have shown that IL6 increases endothelial permeability, a key mechanism in the pathogenesis of urticaria [47]. The levels of this cytokine are indeed higher in patients with $\mathrm{CU}$ than in healthy controls and decrease with remission of urticaria [48]. Interestingly, high circulating levels of IL6 have been also reported in Hashimoto's thyroiditis where they positively correlate with the number of Th22 lymphocytes, which in turn is related to the TPOAbs titre $[49,50]$. Another possible immunopathologic link underlying the association between autoimmune thyroiditis and CU could lie in a defective activity of regulatory T cells (Tregs). Tregs are $\mathrm{T}$ lymphocytes with suppressor properties on effector immune cells, and a decrease in number and/or functionality of Tregs was associate with a variety of autoimmune disorders [51]. Interestingly, decreased percentage and activity of Tregs have been demonstrated both in CU [52-54] and autoimmune thyroid diseases [55, 56]. Unfortunately, the lack of information on these immuno-molecular factors hindered quantitative analyses to clarify their possible pathogenic role.

This meta-analysis has some limitations. First, some potentially relevant studies were not included because of incomplete or unsuitable data. In this regard, only articles published in English language retrievable from well-recognized electronic databases were screened for eligibility. Nevertheless, when the analysis was restricted to TPOAbs, we included more studies than in the only other previously published meta-analysis on the topic [57]. Second, different criteria for the diagnosis of thyroid dysfunction could have made it difficult to compare the studies when the rate of hypothyroidism and hyperthyroidism was analyzed in meta-regression. Moreover, although TPOAbs represent a sensitive marker of autoimmune thyroid disease, their positivity is not a sufficient criterion for the diagnosis of chronic autoimmune thyroiditis and there may be also cases of autoimmune thyroid disease with negative TPOAbs [58]. On the other hand, TPOAbs positivity can be found also in subacute thyroiditis, as well as in non-thyroid autoimmune disorders. Unfortunately, available studies were largely lacking in information about thyroid ultrasonographic features that could have helped in the correct diagnostic framing. As another major limitation, many of the included studies may not be fully comparable due to the different assay methods and cut-offs used to identify TPOAbs positivity (Table 1). These differences may have affected the accuracy of the overall estimate. Finally, unadjusted data were extracted and pooled in our quantitative synthesis: availability of point estimates corrected for confounders would have made it possible to produce a more representative pooled estimate of the true association between $\mathrm{CU}$ and thyroid autoimmunity. To partially overcome this limitation, meta-regressions were conducted that did not demonstrate a significant role as a source of heterogeneity of several possible confounding factors, except for the methodological quality, highlighting that the studies with lower risk of bias found the strongest associations.

In conclusion, people with CU have a five-to-nearly sevenfold higher odd of exhibiting TPOAbs positivity. From a clinical point of view, independently of the pathogenesis underlying such an association, this finding points to the opportunity to perform a screening for thyroid autoimmunity in the presence of $\mathrm{CU}$. This approach could allow identification of patients with chronic autoimmune thyroiditis still in euthyroidism who could benefit from monitoring of TSH levels over time.

Supplementary Information The online version contains supplementary material available at https://doi.org/10.1007/s40618-022-01761-2.

Author contributions Conceptualization: AB and DT. Methodology: $\mathrm{AB}, \mathrm{DT}, \mathrm{CC}$, and MM. Formal analysis and investigation: DT, FDG, LS, CC, MT, and AB. Writing-original draft preparation: DT. Writing - review and editing: $\mathrm{AB}, \mathrm{SF}$, and MGB. Supervision: $\mathrm{AB}$ and MGB.

Funding The authors did not receive support from any organization for the submitted work.

\section{Declarations}

Conflict of interest The authors declare they have no financial interests. Marco Giorgio Baroni and Arcangelo Barbonetti are members of the Editorial Board of the J Endocrinol Invest.

Ethical approval Not applicable.

Research involving human participants and/or animals This is a systematic review with meta-analysis of data produced from studies already published in the literature. Forthis type of study is not required approval of the ethics committee not involving neither animals nor people.

Informed consent For this type of study, formal consent is not required.

Open Access This article is licensed under a Creative Commons Attribution 4.0 International License, which permits use, sharing, adaptation, distribution and reproduction in any medium or format, as long as you give appropriate credit to the original author(s) and the source, provide a link to the Creative Commons licence, and indicate if changes were made. The images or other third party material in this article are included in the article's Creative Commons licence, unless indicated otherwise in a credit line to the material. If material is not included in the article's Creative Commons licence and your intended use is not permitted by statutory regulation or exceeds the permitted use, you will need to obtain permission directly from the copyright holder. To view a copy of this licence, visit http://creativecommons.org/licenses/by/4.0/.

\section{References}

1. Powell RJ, Du Toit GL, Siddique N, Leech SC, Dixon TA, Clark AT, Mirakian R, Walker SM, Huber PA, Nasser SM, British 
Society for Allergy and Clinical Immunology (BSACI) (2007) BSACI guidelines for the management of chronic urticaria and angio-oedema. Clin Exp Allergy 37:631-650

2. Grattan CE (2007) Towards rationalizing the nomenclature and classification of urticaria: some guidance on guidelines. Clin Exp Allergy 37:625-626

3. Kulthanan K, Jiamton S, Thumpimukvatana N, Pinkaew S (2007) Chronic idiopathic urticaria: prevalence and clinical course. J Dermatol 34:294-301

4. Rottem M (2003) Chronic urticaria and autoimmune thyroid disease: is there a link? Autoimmun Rev 2:69-72

5. Dreskin SC, Andrews KY (2005) The thyroid and urticaria. Curr Opin Allergy Clin Immunol 5:408-412

6. Leznoff A, Josse RG, Denburg J, Dolovich J (1983) Association of chronic urticaria and angioedema with thyroid autoimmunity. Arch Dermatol 119:636-640

7. Gaig P, García-Ortega P, Enrique E, Richart C (2000) Successful treatment of chronic idiopathic urticaria associated with thyroid autoimmunity. J Investig Allergol Clin Immunol 10:342-345

8. Ryhal B, DeMera RS, Shoenfeld Y, Peter JB, Gershwin ME (2001) Are autoantibodies present in patients with subacute and chronic urticaria? J Investig Allergol Clin Immunol 11:16-20

9. Gangemi S, Saitta S, Lombardo G, Patafi M, Benvenga S (2009) Serum thyroid autoantibodies in patients with idiopathic either acute or chronic urticaria. J Endocrinol Invest 32:107-110

10. Fusari A, Colangelo C, Bonifazi F, Antonicelli L (2005) The autologous serum skin test in the follow-up of patients with chronic urticaria. Allergy 60:256-258

11. Palma-Carlos AG, Palma-Carlos ML (2005) Chronic urticaria and thyroid autoimmunity. Eur Ann Allergy Clin Immunol $37: 143-146$

12. Confino-Cohen R, Chodick G, Shalev V, Leshno M, Kimhi O, Goldberg A (2012) Chronic urticaria and autoimmunity: associations found in a large population study. J Allergy Clin Immunol 129:1307-1313

13. Díaz-Angulo S, López-Hoyos M, Muñoz Cacho P, Fernández M, López-Escobar M, Rodríguez F, González-López MA (2016) Prevalence of thyroid autoimmunity in spanish patients with chronic idiopathic urticaria: a case-control study involving 343 subjects. J Eur Acad Dermatol Venereol 30:692-693

14. Aamir IS, Tauheed S, Majeed F, Atif A (2008) Serum antithyroid antibodies in female patients with chronic urticaria. J Coll Physicians Surg Pak 18:498-501

15. Cebeci F, Tanrikut A, Topcu E, Onsun N, Kurtulmus N, Uras AR (2006) Association between chronic urticaria and thyroid autoimmunity. Eur J Dermatol 16:402-405

16. Czarnecka-Operacz M, Sadowska-Przytocka A, Jenerowicz D, Szeliga A, Adamski Z, Łącka K (2017) Thyroid function and thyroid autoantibodies in patients with chronic spontaneous urticaria. Postepy Dermatol Alergol 34:566-572

17. Kasumagic-Halilovic E, Beslic N, Ovcina-Kurtovic N (2017) Thyroid autoimmunity in patients with chronic urticaria. Med Arch 71:29-31

18. Magen E, Zueva E, Mishal J, Schlesinger M (2016) The clinical and laboratory characteristics of acute spontaneous urticaria and its progression to chronic spontaneous urticaria. Allergy Asthma Proc 37:394-399

19. Nuzzo V, Tauchmanova L, Colasanti P, Zuccoli A, Colao A (2011) Idiopathic chronic urticaria and thyroid autoimmunity: experience of a single center. Dermatoendocrinol 3:255-258

20. Al-Balbeesi AO (2011) Significance of antithyroid antibodies and other auto-antibodies in Saudi patients with chronic urticaria. Possible parameters in predicting chronic over three years disease. J Saudi Soc Dermatol Dermatologic Surg 15:47-51

21. Alpay A, Solak Tekin N, Tekin IÖ, Altinyazar HC, Koca R, Cinar S (2013) Autologous serum skin test versus autologous plasma skin test in patients with chronic spontaneous urticaria. Dermatol Res Pract. https://doi.org/10.1155/2013/267278

22. Ghaffari J, Khademloo M, Mohammadzadeh I, Golpoor M (2013) Chronic urticaria: the necessity of laboratory examination. Zahedan J Res Med Sci 15:66-68

23. Okba AM, Sheha DS, Moustafa AS, El-Sherbeny AA, Mohamed NA, Aglan MF (2015) Association between thyroid autoimmunity and chronic urticaria in patients versus healthy controls. Egypt J Obes Diabetes Endocrinol 1:84-89

24. Turktas I, Gokcora N, Demirsoy S, Cakir N, Onal E (1997) The association of chronic urticaria and angioedema with autoimmune thyroiditis. Int J Dermatol 36:187-190

25. Verneuil L, Leconte C, Ballet JJ, Coffin C, Laroche D, Izard JP, Reznik Y, Leroy D (2004) Association between chronic urticaria and thyroid autoimmunity: a prospective study involving 99 patients. Dermatology 208:98-103

26. Wan KS, Wu CS (2013) The essential role of anti-thyroid antibodies in chronic idiopathic urticaria. Endocr Res 38:85-88

27. Yadav S, Kanwar A, Parsad D, Minz R (2013) Chronic idiopathic urticaria and thyroid autoimmunity: perplexing association. Indian J Dermatol 58:325

28. Cho CB, Stutes SA, Altrich ML, Ardoin SP, Phillips G, Ogbogu PU (2013) Autoantibodies in chronic idiopathic urticaria and nonurticarial systemic autoimmune disorders. Ann Allergy Asthma Immunol 110:29-33

29. Ferrari SM, Fallahi P, Santaguida G, Virili C, Ruffilli I, Ragusa F, Centanni M, Antonelli A (2017) Circulating CXCL10 is increased in non-segmental vitiligo, in presence or absence of autoimmune thyroiditis. Autoimmun Rev 16:946-950

30. Shamseer L, Moher D, Clarke M, Ghersi D, Liberati A, Petticrew M, Shekelle P, Stewart LA, PRISMA-P Group (2015) Preferred reporting items for systematic review and meta-analysis protocols (PRISMA-P) 2015: elaboration and explanation. BMJ 350:g7647

31. Stroup DF, Berlin JA, Morton SC, Olkin I, Williamson GD, Rennie D, Moher D, Becker BJ, Sipe TA, Thacker SB (2000) Meta analysis of observational studies in epidemiology: a proposal for reporting. JAMA 283:2008-2012

32. Deeks JJ, Dinnes J, D’Amico R, Sowden AJ, Sakarovitch C, Song F, Petticrew M, Altman DG, International Stroke Trial Collaborative Group; European Carotid Surgery Trial Collaborative Group (2003) Evaluating non-randomised intervention studies. Health Technol Assess 7(27):1-173

33. Mantel N, Haenszel W (1959) Statistical aspects of the analysis of data from retrospective studies of disease. J Natl Cancer Inst 22:719-748

34. Greenland S, Robins JM (1985) Confounding and misclassification. Am J Epidemiol 122:495-506

35. Sterne JA, Egger M (2001) Funnel plots for detecting bias in meta-analysis: guidelines on choice of axis. J Clin Epidemiol 54:1046-1055

36. Egger M, Davey Smith G, Schneider M, Minder C (1997) Bias in meta-analysis detected by a simple, graphical test. BMJ 315:629-634

37. Duval S, Tweedie R (2000) Trim and fill: a simple funnel-plotbased method of testing and adjusting for publication bias in metaanalysis. Biometrics 56:455-463

38. Barbonetti A, Martorella A, Minaldi E, D'Andrea S, Bardhi D, Castellini C, Francavilla F, Francavilla S (2019) Testicular cancer in infertile men with and without testicular microlithiasis: a systematic review and meta-analysis of case-control studies. Front Endocrinol (Lausanne) 10:164

39. Di Lorenzo G, Leto-Barone MS, La Piana S, Seidita A, Rini GB (2013) Chronic spontaneous urticaria: an autoimmune disease? A revision of the literature. Clin Exp Med 13:159-164 
40. Berghi NO (2017) Immunological mechanisms implicated in the pathogenesis of chronic urticaria and hashimoto thyroiditis. Iran J Allergy Asthma Immunol 16:358-366

41. Gonzalez-Diaz SN, Sanchez-Borges M, Rangel-Gonzalez DM, Guzman-Avilan RI, Canseco-Villarreal JI, Arias-Cruz A (2020) Chronic urticaria and thyroid pathology. World Allergy Organ J 13:100101

42. Aversano M, Caiazzo P, Iorio G, Ponticiello L, Laganá B, Leccese $F$ (2005) Improvement of chronic idiopathic urticaria with L-thyroxine: a new TSH role in immune response? Allergy 60:489-493

43. Koh CK, Hew FL, Chiu CL (2000) Treatment of chronic urticaria with thyroxine in an euthyroid patient with thyroglobulin and microsomal antibodies. Ann Acad Med Singap 29:528-530

44. Kiyici S, Gul OO, Baskan EB, Hacioglu S, Budak F, Erturk E, Imamoglu S (2010) Effect of levothyroxine treatment on clinical symptoms and serum cytokine levels in euthyroid patients with chronic idiopathic urticaria and thyroid autoimmunity. Clin Exp Dermatol 35:603-607

45. Magen E, Mishal J (2012) The effect of L-thyroxine treatment on chronic idiopathic urticaria and autoimmune thyroiditis. Int $\mathrm{J}$ Dermatol 51:94-97

46. Eckman JA, Hamilton RG, Gober LM, Sterba PM, Saini SS (2008) Basophil phenotypes in chronic idiopathic urticaria in relation to disease activity and autoantibodies. J Invest Dermatol 128:1956-1963

47. Tanaka T, Kishimoto T (2014) The biology and medical implications of interleukin-6. Cancer Immunol Res 2:288-294

48. Kasperska-Zajac A, Sztylc J, Machura E (2011) Plasma IL-6 concentration correlates with clinical disease activity and serum C-reactive protein concentration in chronic urticaria patients. Clin Exp Allergy 41:1386-1391

49. Bai X, Sun J, Wang W, Shan Z, Zheng H, Li Y, Zhao Y, Gong M, Teng W (2014) Increased differentiation of Th22 cells in Hashimoto's thyroiditis. Endocr J 61:1181-1190

50. Al-Jameil N, Khan MF, Al-Rashid M, Tabassum H (2015) Thyroid dysfunction: an autoimmune aspect. Int J Clin Exp Med 8(5):6677
51. Valencia X, Lipsky PE (2007) CD4+ CD25+ FoxP3+ regulatory $\mathrm{T}$ cells in autoimmune diseases. Nat Clin Pract Rheumatol 3(11):619-626

52. Arshi S, Babaie D, Nabavi M, Tebianian M, Ghalehbaghi B, Jalali F, Ahmadvand A, Gholami R (2014) Circulating level of CD4+ CD25+ FOXP3+ T cells in patients with chronic urticaria. Int $\mathrm{J}$ Dermatol 53:e561-e566

53. Sun RS, Sui JF, Chen XH, Ran XZ, Yang ZF, Guan WD, Yang $T$ (2011) Detection of CD4+ CD25+ FOXP3+ regulatory T cells in peripheral blood of patients with chronic autoimmune urticaria. Australas J Dermatol 52:e15-e18

54. Chen WC, Chiang BL, Liu HE, Leu SJ, Lee YL (2008) Defective functions of circulating CD4+CD25+ and CD4+CD25- T cells in patients with chronic ordinary urticaria. J Dermatol Sci 51:121-130

55. Glick AB, Wodzinski A, Fu P, Levine AD, Wald DN (2013) Impairment of regulatory $\mathrm{T}$-cell function in autoimmune thyroid disease. Thyroid 23:871-878

56. Xue H, Yu X, Ma L, Song S, Li Y, Zhang L, Yang T, Liu H (2015) The possible role of $\mathrm{CD} 4^{+} \mathrm{CD} 25$ (high)Foxp $3^{+} / \mathrm{CD} 4^{+} \mathrm{IL}-17 \mathrm{~A}^{+}$cell imbalance in the autoimmunity of patients with Hashimoto thyroiditis. Endocrine 50:665-673

57. Pan XF, Gu JQ, Shan ZY (2015) The prevalence of thyroid autoimmunity in patients with urticaria: a systematic review and metaanalysis. Endocrine 48:804-810

58. Rotondi M, Coperchini F, Magri F, Chiovato L (2014) Serumnegative autoimmune thyroiditis: what's in a name? J Endocrinol Invest 37:589-591

Publisher's Note Springer Nature remains neutral with regard to jurisdictional claims in published maps and institutional affiliations. 